\title{
Assessment of the impact of speed limit reduction and traffic signal coordination on vehicle emissions using an integrated approach
}

\author{
Madhava Madireddy ${ }^{\mathrm{a}, \mathrm{b}}$, Bert De Coensel ${ }^{\mathrm{a}, *}$, Arnaud Can ${ }^{\mathrm{a}}$, Bart Degraeuwe $^{\mathrm{b}}$, \\ Bart Beusen $^{\mathrm{b}}$, Ina De Vlieger ${ }^{\mathrm{b}}$, Dick Botteldooren ${ }^{\mathrm{a}}$ \\ ${ }^{a}$ Ghent University, Department of Information Technology, Acoustics research group, \\ St.-Pietersnieuwstraat 41, B-9000 Ghent, Belgium \\ ${ }^{b}$ Flemish Institute for Technological Research (VITO), Boeretang 200, B-2400 Mol, Belgium
}

\begin{abstract}
This paper examines the effects of two traffic management measures, speed limit reduction and coordinated traffic lights, in a case study area in Antwerp, Belgium. For this purpose, an integrated model that combines the microscopic traffic simulation model Paramics with the $\mathrm{CO}_{2}$ and $\mathrm{NO}_{\mathrm{x}}$ emission model VERSIT+ is constructed and validated. On the one hand, reductions in $\mathrm{CO}_{2}$ and $\mathrm{NO}_{\mathrm{x}}$ emissions in the order of $25 \%$ were found if speed limits are lowered from 50 to $30 \mathrm{~km} / \mathrm{h}$ in the residential part of the case study area. On the other hand, reductions in the order of $10 \%$ can be expected from the implementation of a green wave signal coordination scheme along an urban arterial road.
\end{abstract}

Keywords: Microscopic traffic simulation, $\mathrm{CO}_{2}, \mathrm{NO}_{\mathrm{x}}$, Speed limits, Traffic light synchronization, Green wave

\section{Introduction}

With the increasing amount of road traffic in urban areas in the last few decades, controlling congestion and vehicle related emissions have become major challenges for

4 city planners. Congestion increases travel times and idling, and because of this, urban 5 regions are facing increasing concentrations of air pollutants. Next to this, the rise of

\footnotetext{
*Corresponding author. Tel.: +329264 9994; fax: +3292649969.

Email address: bert.decoensel@intec.ugent. be (Bert De Coensel)
} 
atmospheric carbon dioxide, which is a major greenhouse gas, has become a matter of concern. A number of traffic management measures are therefore considered in various cities, such as diverting traffic from peak hours to off-peak hours using congestion pricing, reducing speed limits, coordinating traffic lights along major arterials, replacing signalized intersections with roundabouts, or even adding additional lanes where expanding the road network is feasible.

It is widely acknowledged that if the number of acceleration and deceleration events, associated with stop-and-go traffic, is reduced, fuel efficiency increases and emissions are reduced (El-Shawarby et al., 2005; Int Panis et al., 2006). On the one hand, optimized signal timing (Li et al., 2004; Pandian et al., 2009) and coordinated traffic lights (Zito, 2009) are increasingly applied along major arterials, in order to smoothen traffic flow. Usually, systems are designed to create green waves along arterial roads facing high demands. On the other hand, speed reductions, such as through the introduction of zones with a $30 \mathrm{~km} / \mathrm{h}$ speed limit, are becoming popular for protecting residential areas, as they provide benefits in terms of road safety, traffic diversion, as well as smoother flows and reduced emissions (Int Panis et al., 2006).

Because it is often infeasible to employ a trial-and-error method for assessing the environmental effects of traffic management measures, microscopic simulation models are increasingly employed for this purpose; see e.g. De Coensel et al. (2007) for the case of noise emissions or Smit and McBroom (2009) for the case of air pollutant emissions. Microscopic traffic models consider the behavior of individual vehicles, which are modelled to obey empirically based rules for car following, lane changing and overtaking (Helbing, 2001). They allow to estimate the impact of detailed measures, because the influence of braking and acceleration is taken into account. However, they require a large amount of detail in input data (road layout, signal timings, traffic counts, etc.), and are therefore mainly useful to study traffic management measures within small to medium sized areas, such as a part of a city. Next to this, computational models for estimating pollutant emissions that return realistic results for the stop-and-go behavior of vehicles in urban environment have not been available until recently.

In the present paper, the effects of traffic management measures on the $\mathrm{CO}_{2}$ and 
$\mathrm{NO}_{\mathrm{x}}$ emissions in a part of the city of Antwerp, Belgium, are evaluated. For this purpose, a microscopic traffic model in combination with a state-of-the-art air pollutant emission model is employed. In Section 2, the construction of the traffic network model for the case study area is presented, together with a validation of the integrated model. In Section 3, the effects of a speed limit reduction and of traffic signal coordination on emissions are presented. The approach presented could be of inspiration for the construction of guidance tools for urban planning practice.

\section{Methodology and validation}

\subsection{Case study area}

The case study area, called "Zurenborg", is located in the southeastern part of the 19th century city belt of Antwerp, Belgium. Figure 1 shows a map of the region. In the east, the area is bounded by the R1 freeway, on which a speed limit of $100 \mathrm{~km} / \mathrm{h}$ holds, and a major road (the R10 or "Singel"), with a speed limit of $70 \mathrm{~km} / \mathrm{h}$. In the southwest, the area is bounded by a railway track. In the north, the area is bounded by a major arterial road (the N184 or "Plantin en Moretuslei"), which connects the city of Antwerp (situated at the west side of the area) with suburban areas in the east. This road has 2 lanes in each direction, and implements traffic signal coordination. More in particular, during morning rush hour, all signals along this road operate at the same cycle time ( $60 \mathrm{~s}$ to $90 \mathrm{~s}$, depending on the presence of pedestrians or buses), and the temporal offset of the cycle of each intersection is set such that vehicles travelling from east to west encounter only green lights, when driving at the desired speed of $50 \mathrm{~km} / \mathrm{h}$. A similar traffic signal setting is applied in the reverse direction during the evening rush hour. Traffic intensity during morning rush hour, from east to west, varies between 700 and 1000 vehicles/hour, depending on the segment that is considered (vehicles also enter along the side streets). The triangular area within the eastern, southwestern and northern borders is mainly residential, with an overall speed limit of $50 \mathrm{~km} / \mathrm{h}$.

\subsection{Microscopic traffic simulation model}

In this work, Quadstone Paramics, a commercially available microscopic traffic simulation tool, is used as the modelling software. A simulation network of the tri- 


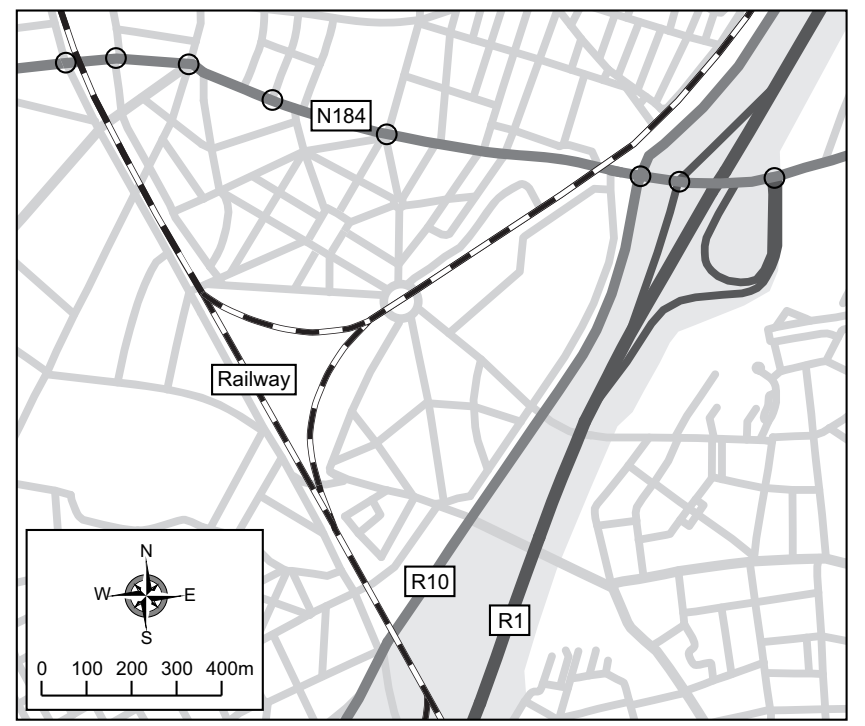

Figure 1: Map of the case study area "Zurenborg" in Antwerp, Belgium. The triangular area bounded by the R1, the N184 and the railway forms the outline of the traffic simulation network. The circles along the N184 mark signalized intersections with coordinated traffic lights.

angular case study area was constructed on the basis of GIS (Geographic Information System) data and aerial photographs, which supplied the detailed positions of all roads and buildings in the study area. Network wide traffic demands were calibrated for the morning rush-hour, based on traffic counts made available by the Flemish Department of Mobility and Public Works. Traffic signal parameters (cycle times, signal offsets between intersections etc.) were set according to the actual situation, based on data obtained from the Antwerp police department. Two types of vehicles (light and heavy duty) were considered, which were linked to the respective emission classes of the emission model (see Section 2.3). The railway passing through the study area was not modelled. The simulation time considered was $1 \mathrm{~h}$, with a timestep of $0.5 \mathrm{~s}$. Vehicles are loaded onto the network at the edge roads along the sides of the network, according to the traffic demands. During simulation, the position, speed and acceleration of each vehicle is recorded at each timestep, for subsequent calculation of emissions.

It should be noted that, although the microscopic traffic model is able to take into 
account a wide range of vehicle driving behavior, a number of factors that have an influence on vehicle speeds and accelerations cannot be (fully) taken into account. Among those are the influence of pedestrians crossing the street, cars slowing down to park or cars leaving a parking spot, or the full extent of the stochastic component in driver's behavior. Next to this, the traffic counts used to calibrate the model reflect the average situation during morning rush hour. Therefore, traffic counts and speed distributions measured at a single instant in time within the simulated region could significantly differ from those that are simulated. Nevertheless, as only average trends are usually considered, microscopic traffic simulation models are increasingly being applied for estimating the emissions from traffic flows. Earlier work has shown that, for emission modelling purposes, a reasonably good agreement between simulated and measured speeds and accelerations can be achieved (De Coensel et al., 2005).

\subsection{Emission model}

The instantaneous $\mathrm{CO}_{2}$ and $\mathrm{NO}_{\mathrm{x}}$ emission of each vehicle in the simulation is calculated using the VERSIT+ vehicle exhaust emission model, based on the speeds and accelerations extracted from the traffic model. The VERSIT + model, developed by TNO (Smit et al., 2007), is based on more than 12,500 measurements on vehicles of a wide range of makes and models, fuel types, Euro class, fuel injection technology, types of transmission etc. The model uses multivariate regression techniques to determine emission factors for different vehicle classes. As the model requires actual driving pattern data as input, it is fully capable of accounting for the effects of congestion on emission. A derived model was recently developed by TNO (Ligterink and De Lange, 2009), specifically targeted at a coupling with microscopic traffic simulation models. For this, emission parameters of different vehicles (with varying age, fuel type etc.) were aggregated into a prototypical vehicle emission model representing the average emission of the Dutch vehicle fleet. While there may be differences between individual vehicles, the model is aimed at predicting measurement results aggregated over a sufficiently large number of vehicles sampled from the Dutch vehicle fleet. In this work, the VERSIT+ light and heavy duty vehicle classes representing the fleet in Dutch urban environments during the year 2009 was used. Finally, it has to be noted 
that only emissions are considered in this paper; the dispersion of air pollutants is not modelled.

A small-scale validation of the dynamic properties of the emission model was carried out using VOEM, VITO's on-road emission and energy measurement system (De Vlieger, 1997). Measurements of instantaneous speed, acceleration, $\mathrm{CO}_{2}$ and $\mathrm{NO}_{\mathrm{x}}$ emissions were carried out using 4 different diesel vehicles subjected to the MOL30 driving cycle, which is based on real driving behavior in urban, suburban and freeway traffic situations. Subsequently, the emission model was used to estimate the $\mathrm{CO}_{2}$ and $\mathrm{NO}_{\mathrm{x}}$ emissions based on measured speeds and accelerations. Finally, both measured and estimated emission time series were compared. In general, a good dynamic agreement was found, with temporal correlation factors $r^{2}=0.90 \pm 0.03$ for $\mathrm{CO}_{2}$ and $r^{2}=0.72 \pm 0.10$ for $\mathrm{NO}_{\mathrm{x}}$ for all test vehicles, indicating that the model is able to capture the dependencies on speed and acceleration well. The somewhat lower correlations for $\mathrm{NO}_{\mathrm{x}}$ may be explained by the presence of an Exhaust Gas Recirculation (EGR) system in some of the vehicles considered. More details on this validation can be found in Trachet et al. (2010).

\subsection{Validation of the integrated model}

The accuracy of the integrated model (combination of traffic and emission models) concerning the estimation of emissions is examined using data from a series of actual vehicle trips through the case study area. On the one hand, a vehicle equipped with data logging devices was driven several times along the N184 on a typical working day. Instantaneous speed, throttle position and fuel consumption were gathered through the CAN-bus interface of the vehicle on a second-by-second basis, while the vehicle location was logged using a GPS device. On the other hand, trip data for all (light duty) vehicles driving along the N184 was extracted from the microsimulation model.

In both cases, only the part of the trip along the N184 was considered. Subsequently, instantaneous emissions were calculated using the emission model, for both measured and simulated vehicle trips. Figure 2 shows the normalized distribution of calculated $\mathrm{CO}_{2}$ and $\mathrm{NO}_{\mathrm{x}}$ emissions per $\mathrm{km}$, for the measured and simulated vehicle trips. In general, a good agreement was found between both, suggesting that the accuracy of the 

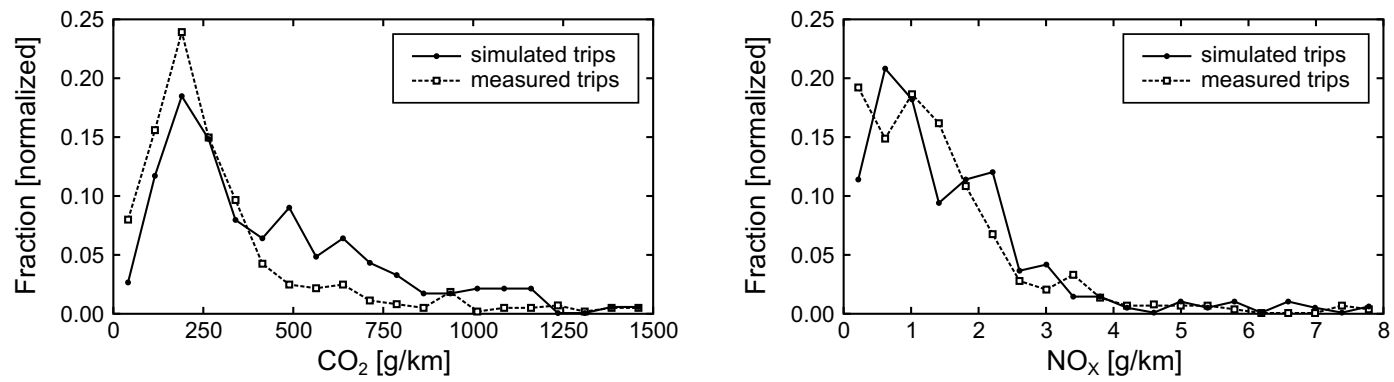

Figure 2: Normalized distributions of $\mathrm{CO}_{2}$ and $\mathrm{NO}_{\mathrm{x}}$ emissions per $\mathrm{km}$, for both measured and simulated vehicle trips along the $\mathrm{N} 184$.

integrated model is sufficient for estimating the effects of traffic management measures on emissions.

\section{Simulation results}

\subsection{Effect of reduced speed limits}

As a first traffic management measure, the effect of a speed limit reduction is studied. Based on potential measures that are currently being considered by the traffic planning authorities of the city of Antwerp, speed limits are reduced from 100 to $70 \mathrm{~km} / \mathrm{h}$ on the freeway, from 70 to $50 \mathrm{~km} / \mathrm{h}$ on the Singel, and from 50 to $30 \mathrm{~km} / \mathrm{h}$ on the other residential roads and the N184. For the latter, the traffic signal coordination was recalibrated for the lower speed limit, in order to have a green wave as in the original scenario. It should be noted that the microscopic traffic simulation model applies dynamic traffic assignment: routes are chosen according to the instantaneous congestion conditions. Traffic demands were kept constant.

Changes in the distribution of instantaneous speeds and accelerations for vehicles driving within the residential part of the network (excluding the N184, R10 and R1) are presented in Figure 3. It can be seen that, next to a reduction in average speeds, the speed distribution becomes more narrow, coupled with a reduction in the occurrence of maximum acceleration events. Hence, the speed limit reduction resulted in a smoother traffic flow in the residential area. Note that maximum speeds are about $10 \%$ above 

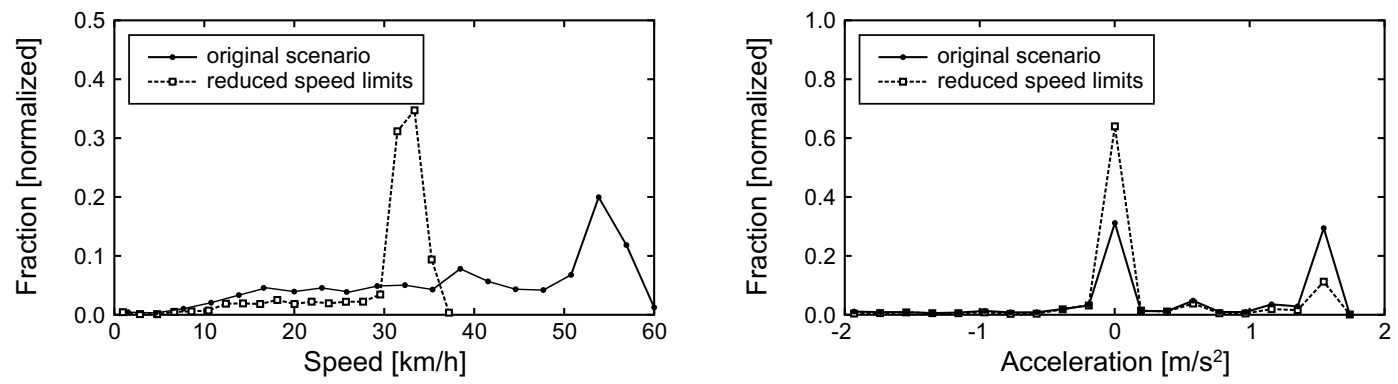

Figure 3: Normalized distributions of instantaneous speed and acceleration, for vehicles driving within the residential part of the network.
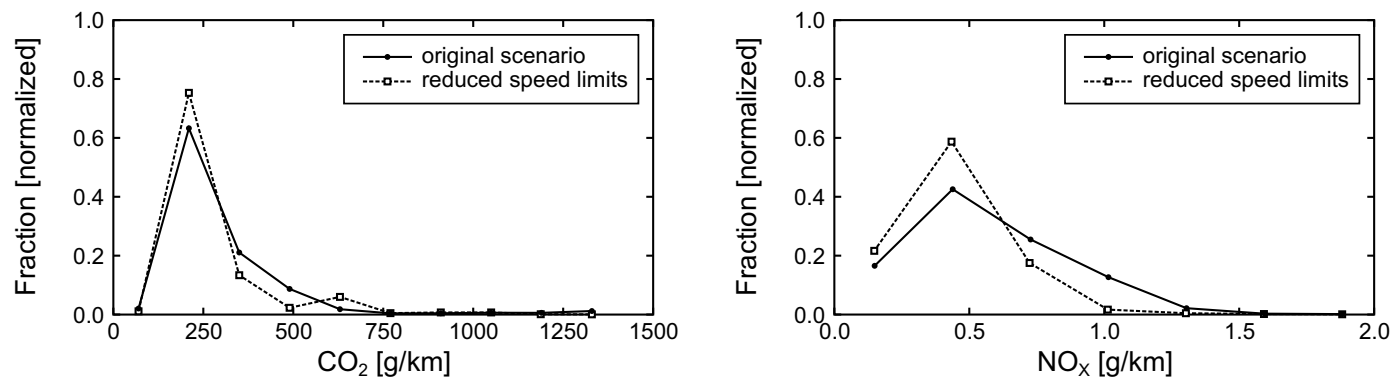

Figure 4: Normalized distributions of $\mathrm{CO}_{2}$ and $\mathrm{NO}_{\mathrm{x}}$ emissions per $\mathrm{km}$, for vehicles driving within the residential part of the network.

the speed limits, as the traffic model also accounts for speeding, in order to resemble the actual situation as close as possible. Figure 4 shows the corresponding change in distribution of instantaneous distance-based emissions for the light duty vehicles; the results for heavy duty vehicles show a similar trend. The total distance travelled by all vehicles within the residential area reduced by $14.1 \%$ because of traffic rerouting. However, total $\mathrm{CO}_{2}$ and $\mathrm{NO}_{\mathrm{x}}$ emissions reduced by resp. $26.8 \%$ and $26.7 \%$. Consequently, also a reduction in distance based emissions was found, as can be seen in Figure 4. For the vehicles driving along the N184, similar results are found. Although the total distance travelled by all vehicles along the N184 was reduced only slightly by $0.2 \%$, still, a reduction in $\mathrm{CO}_{2}$ and $\mathrm{NO}_{\mathrm{x}}$ emissions by resp. $9.9 \%$ and $10.4 \%$ was found. 

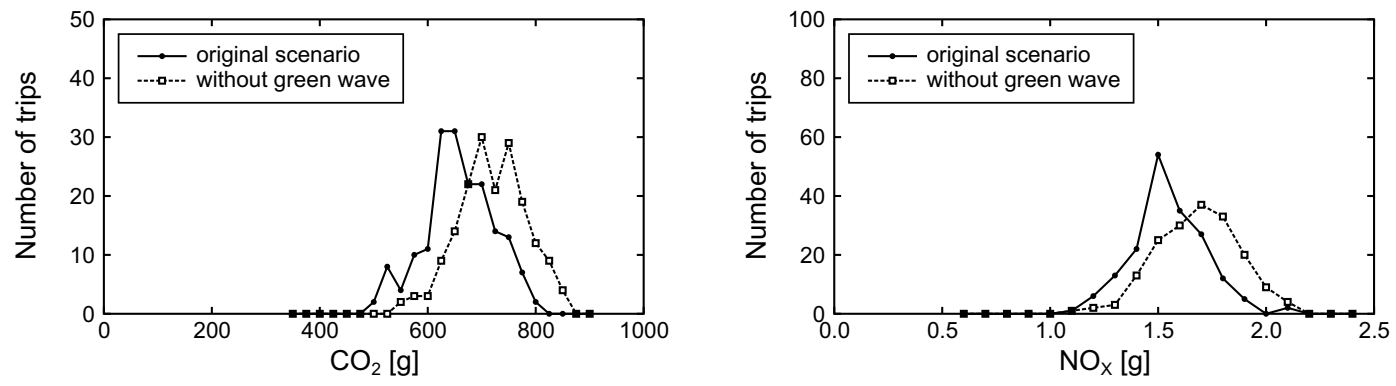

Figure 5: Distributions of total $\mathrm{CO}_{2}$ and $\mathrm{NO}_{\mathrm{x}}$ emissions, for (light duty) vehicle trips along the $\mathrm{N} 184$.

\subsection{Effect of traffic light coordination}

As a second traffic management measure, the effect of traffic signal coordination along the N184 is studied. The original situation, with implementation of a green wave from east to west, is compared to the scenario in which the coordination is removed. In order to desynchronize the traffic signals, a small but random number of seconds ( $\leq 2 \mathrm{~s})$ is added to or subtracted from the cycle times of all traffic lights along the N184. This way, a wide range of waiting times and queue lengths at each intersection is encountered over the course of the simulation run. The results for this desynchronized scheme will thus represent the average over the results for all possible schemes in which there is no signal coordination. Again, traffic demands were kept constant.

Figure 5 shows the changes in the distribution of total trip emissions for all light duty vehicles that drove along the N184, and that completed their trip during the simulation run (only the part of the trip along the N184 is considered). It was found that $\mathrm{CO}_{2}$ and $\mathrm{NO}_{\mathrm{x}}$ emissions increased by resp. $9.5 \%$ and $8.7 \%$ when the signal coordination was removed (light and heavy duty vehicles combined). Consequently, the implementation of traffic signal coordination along the N184 resulted in a reduction of air pollutant emissions because of a smoother traffic flow.

\section{Conclusions}

An integrated approach to assess the impact of traffic management measures on $\mathrm{CO}_{2}$ and $\mathrm{NO}_{\mathrm{x}}$ emissions was presented. The methodology consists of coupling a mi- 
croscopic traffic simulation model with a state-of-the-art instantaneous air pollutant emission model. The latter was validated using a set of vehicles equipped with onboard measurement tools, and a good agreement was found between measurements and simulations. The above described approach differs from earlier work in that modelling results are representative for a complete vehicle fleet (in this case the Dutch fleet), and that this is accomplished through a well-calibrated emission model, instead of using a wide range of different vehicle categories in the traffic simulation model, which makes for an easier calibration of the latter.

This study reaffirms the environmental benefits of reducing speed limits in residential areas, which is caused by the combination of traffic rerouting and a smoother traffic flow at lower average speed. Reductions in $\mathrm{CO}_{2}$ and $\mathrm{NO}_{\mathrm{x}}$ emissions in the order of $25 \%$ were found if speed limits are lowered from 50 to $30 \mathrm{~km} / \mathrm{h}$ in residential area, on top of the increased road safety that is expected from lower vehicle speeds. The present study also concludes that a reduction in the order of $10 \%$ in $\mathrm{CO}_{2}$ and $\mathrm{NO}_{\mathrm{x}}$ emissions can be expected from the implementation of a green wave signal coordination scheme. However, it has to be noted that traffic signal coordination also decreases travel times, and the effect of facilitating traffic flow may, in the long term, induce additional traffic (Kitamura, 2009). This side effect potentially offsets the beneficial environmental consequences of signal coordination, or could even make the situation worse (Stathopoulos and Noland, 2003).

\section{Acknowledgments}

The authors are grateful to the Flemish Department of Mobility and Public works for providing traffic counts, and to the Antwerp police department for providing traffic light timings for the case study area. The authors would also like to thank Stijn Vernaillen for gathering real-time speed profiles which were used to validate the traffic model. This study was performed within the framework of Steunpunt Mobiliteit, which is supported by the Flemish Government. Bert De Coensel is a postdoctoral fellow, and Arnaud Can is a visiting postdoctoral fellow of the Research Foundation-Flanders (FWO-Vlaanderen); the support of this organization is also gratefully acknowledged. 


\section{References}

De Coensel, B., Botteldooren, D., Vanhove, F., Logghe, S., 2007. Microsimulation based corrections on the road traffic noise emission near intersections. Acta Acust. Acust. 93, 241-252.

De Coensel, B., De Muer, T., Yperman, I., Botteldooren, D., 2005. The influence of traffic flow dynamics on urban soundscapes. Appl. Acoust. 66, 175-194.

De Vlieger, I., 1997. On-board emission and fuel consumption measurement campaign on petrol-driven passenger cars. Atmos. Environ. 31, 3753-3761.

El-Shawarby, I., Ahn, K., Rakha, H., 2005. Comparative field evaluation of vehicle cruise speed and acceleration level impacts on hot stabilized emissions. Transport. Res. D 10, 13-30.

Helbing, D., 2001. Traffic and related self-driven many-particle systems. Rev. Mod. Phys. 73, 1067-1141.

Int Panis, L., Broekx, S., Liu, R., 2006. Modelling instantaneous traffic emission and the influence of traffic speed limits. Sci. Total Environ. 371, 270-285.

Kitamura, R., 2009. The effects of added transportation capacity on travel: a review of theoretical and empirical results. Transportation 36, 745-762.

Li, X., Li, G., Pang, S.S., Yang, X., Tian, J., 2004. Signal timing of intersections using integrated optimization of traffic quality, emissions and fuel consumption: a note. Transport. Res. D 9, 401-407.

Ligterink, N.E., De Lange, R., 2009. Refined vehicle and driving-behaviour dependencies in the VERSIT+ emission model, in: Proceedings of the Joint 17th Transport and Air Pollution Symposium and 3rd Environment and Transport Symposium (ETTAP), Toulouse, France.

Pandian, S., Gokhale, S., Ghoshal, A.K., 2009. Evaluating effects of traffic and vehicle characteristics on vehicular emissions near traffic intersections. Transport. Res. D 14, 180-196. 
Smit, R., McBroom, J., 2009. Use of microscopic simulation models to predict traffic emissions. Road Transp. Res. 18, 49-54.

Smit, R., Smokers, R., Rabé, E., 2007. A new modelling approach for road traffic emissions: VERSIT+. Transport. Res. D 12, 414-422.

Stathopoulos, F.G., Noland, R.B., 2003. Induced travel and emissions from traffic flow improvement projects, in: Proceedings of the 82nd Annual Meeting of the Transportation Research Board, Washington D.C., USA.

Trachet, B., Madireddy, M., Botteldooren, D., De Vlieger, I., 2010. The influence of traffic management on emissions: literature study of existing emission models and initial tests with microscopic traffic simulation. Technical Report RA-MOW2010-001. Flemish Policy Research Centre for Mobility \& Public Works. Brussels, Belgium.

Zito, P., 2009. Influence of coordinated traffic lights parameters on roadside pollutant concentrations. Transport. Res. D 14, 604-609. 